\title{
Morphology of the Typical Cervical Vertebral Body and Spinal Canal - Applicability of Torg-Pavlov Ratio In Nigeria
}

\author{
*A. I. Udoaka (FWACS), Ewulike Chisom \\ *Department of Anatomy, College of Health Sciences \\ University of Port Harcourt, P .M.B 5323, Port Harcourt \\ alabaudoaka@yahoo.com
}

\begin{abstract}
The morphometry of the cervical spine is of clinical importance in traumatic, degenerative and inflammatory conditions. For example a small diameter has been associated with an increase of injury mainly in athletes who participate in contact or collision sports. Before abnormal spinal morphometry can be determined, it is first necessary to establish normal values for the specific patient population being evaluated. Methods: Subject (300) were randomly chosen from the various hospital radiology imaging data bank alongside their medical report in only those reported as normal were utilized. The typical cervical vertebrae C3-C5 were utilized for this study. Subjects demographic variables which include age and sex were recorded alongside the anthropological variables which include the length and width of the vertebral body, the size of the spinal canal. Result: The mean values obtained in all the variables (vertebral body length and breadth, the saggital and transverse spinal canal) showed a decrease as descends the vertebrae C3, C4, C5 with the vertebral length $(20.44 \pm 2.12 \mathrm{~mm}, 19.7 \pm 2.43)$, the vertebral body's width $(12.89 \pm 1.78 \mathrm{~mm}$,$) and transverse spinal canal$ $(11.74 \pm 1.53 \mathrm{~mm}, 11.21 \pm 1.47 \mathrm{~mm}, 11.19 \pm 1.31)$. Conclusion: This study has indeed showed that the gender difference, decrease in vertebral body size from C3 to C5. The Torg Pavlov ratio is however applicable to Nigerians. The result of the present work may help in better understanding of morphological parameters of cervical spine region of Nigerian population. It may be further useful in designing spinal implants which would be biomechanically compatible to the anatomy of Nigeria people.
\end{abstract}

Keywords: Cervical vertebrae, Nigerian, spinal canal, Torg Pavlov ratio.

\section{INTRODUCTION}

The Human spine protects the spinal cord and nerve roots. The cervical spine forms the skeleton of the neck, it transmits weight of the upper body to the pelvis and therefore is subject to internal stress. Several authors [1 - 2]. Have studied the morphometry of the cervical spine using cadaveric specimens and lately radiologic means.

The size of the spinal canal has also been a subject of interest as the smaller spinal canal dimension have been implicated in cervical myelopathy [3] as a result this prompted the Torg - Pavlov ratio which was statistically approximated in determining cervical stenosis [4]. This ratio is the value of the spinal canal sagittal diameter divided by the corresponding vertebral body length on a lateral radiograph. Any value less than 0.8 is taken as Cervical Stenosis.

This has however made a lot of authors to study their local populations to ascertain the reliability of the Torg - Pavlov ratio [5 - 11]. Their result show marked variability the Torg - Pavlov ratio has however been accepted in some populations as a predictor of acute spinal cord injury. After minor frauma to the Cervical Spine, patients at risk can be identified by applying a Torg - Pavlov ratio cut off of 0.7 [11, 17]. Studies on athletes have also shown that athletes with canal stenosis have greater susceptibility to cervical myelopathy from minor injuries [17-18].

The aim of this study therefore is to determine the normal range of the typical cervical vertebrae morphometry in Nigeria and to compare same to other populations.The study is also aimed at estimating the Torg - Pavlov ratio and its applicability in Nigeria.

\section{MAterials AND Method}

This study was carried out in Nigeria. A total number of three hundred (300) standard radiographs of adult cervical vertebrae (lateral views) were randomly selected for the research. These radiographs were sought out from the achieved of the radiology department of the following hospitals, these were: 
University of Port Harcourt Teaching Hospital, Braithwaite Memorial Specialist Hospital and Astiford and Patrice Clinic all situated in Port Harcourt.

The radiographs were reported to be normal. The age, gender and nationality and other biometric profile were noted.

Anthropometrical variables on each radiograph were measured. There include the vertebral body length (VBL), vertebral body height $(\mathrm{H})$.

(VBL). The Vertebral Body Height (H) this is the Height of the Vertebral Body.

i. For the measurement of vertebral Body Length (VBL).

- Two lines are drawn tangential to the ends of the posterior and anterior vertebrae body margins. $\mathrm{PH} \& \mathrm{AH}$ are marked and a horizontal line is drawn to meet the mid points. This line is the Vertebral Body Length (VBL).

\section{ii. For the Measurement of the Height}

Another vertical line is drawn at the mid point of the VBL and perpendicular to it. This line touched the inferior and superior end plates. This is the vertebral body height $(\mathrm{H})$.

For the Spinal Canal Diameter

- A line is drawn from the mid point of line $(\mathrm{PH})$ to the mid point of the corresponding spinolaminat line. This is the saggital Spinal Canal Diameter (SCD). The Torg - Pavlov ratio is then calculated as $\quad \frac{S S D}{V B L}$ and values obtained. Data recorded were analyzed statistically using APSS version 17 to ascertain mean, standard deviation and test of significance in each gender and the general population studied.

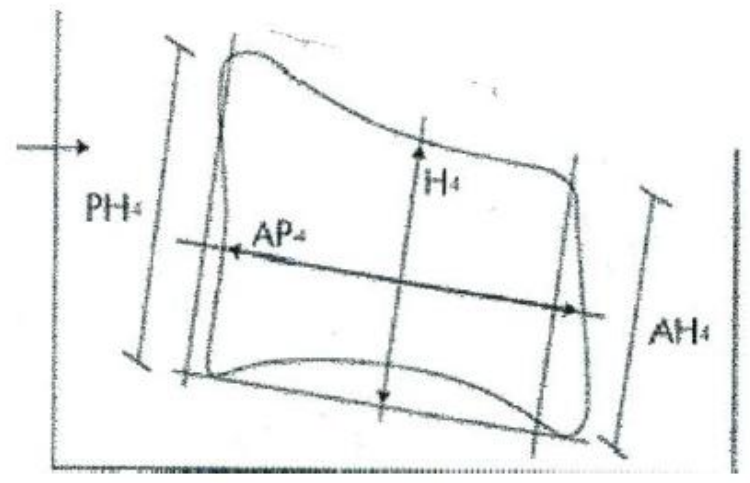

\section{RESULTS AND DISCUSSION}

The typical cervical vertebrae bodies of $\mathrm{C} 3, \mathrm{C} 4$ and $\mathrm{C} 5$ were studied with their spinal canals. The mean values obtained in the vertebral body length (VBL) of the general population for C3, C4, C5 were $20.44 \pm 1.81 \mathrm{~mm}, 19.88 \pm 2.12 \mathrm{~mm}, 19.76 \pm 2.43 \mathrm{~mm}$ respectively out of which males had mean values of $20.44 \pm 0.81 \mathrm{~mm}, 20.76 \pm 1.90 \mathrm{~mm}, 20.52 \pm 2.0 \mathrm{~mm}$ and female mean values were $20.04 \pm$ $1.80 \mathrm{~mm}, 19.00 \pm 2.10 \mathrm{~mm}, 19.00 \pm 2.53 \mathrm{~mm}$. The height of the vertebrae had mean values of $12.89 \pm$ $1.85 \mathrm{~mm}$ for $\mathrm{C} 3,12.59 \pm 1.88 \mathrm{~mm}$ for $\mathrm{C} 412.45 \pm 1.79 \mathrm{~mm}$ for $\mathrm{C} 5$. The males had higher values of $12.73 \pm 1.82 \mathrm{~mm}, 12.89 \pm 1.86 \mathrm{~mm}$ and $12.72 \pm 1.99 \mathrm{~mm}$ than the females that had $12.73 \pm 1.88 \mathrm{~mm}$, $12.29+1.90 \mathrm{~mm}$ and $12.15 \pm 1.91 \mathrm{~mm}$ respectively for $\mathrm{C} 3, \mathrm{C} 4$, and $\mathrm{C} 5$. In all the parameters, the males had large values, this is in keeping with other authors [9, 20, 21].

The spinal canal mid sagittal diameter measured showed values which are also at variance with other populations[20 - 23]. Our values were larger at the three vertebral levels studied.

The Torg - Pavlov's ratio in this study was about the same in all the vertebral levels for both gender. This is in contrast to some authors that recorded smaller ratios for men [3, 23, 24].

Other authors [10] however reported that women had higher Torg - Pavlov's ratio than the men.

Our younger adults had smaller vertebrae body size and spinal cord than the older ones, this is contrary to the findings of other authors [24] which showed larger sizes for the younger population. 
Table1. General Descriptive Statistics

\begin{tabular}{|l|c|c|c|c|}
\hline Parameters & $\begin{array}{c}\text { VBL } \\
(\mathbf{m m}) \\
\text { Mean } \pm \text { SD }\end{array}$ & $\begin{array}{c}\text { H } \\
(\mathbf{m m}) \\
\text { Mean } \mathbf{~ S D ~}\end{array}$ & $\begin{array}{c}\text { SCD } \\
(\mathbf{m m}) \\
\text { Mean } \pm \text { SD }\end{array}$ & $\begin{array}{c}\text { Torg - Parlor } \\
\text { Ratio } \\
\text { Mean } \pm \text { SD }\end{array}$ \\
\hline C3 & $20.44 \pm 1.81$ & $12.89 \pm 1.85$ & $19.59 \pm 1.65$ & $0.96 \pm 0.12$ \\
C4 & $19.88 \pm 2.12$ & $12.59 \pm 1.88$ & $19.03 \pm 1.78$ & $0.95 \pm 0.15$ \\
C5 & $19.76 \pm 2.43$ & $12.45 \pm 1.79$ & $18.99 \pm 2.08$ & $0.95 \pm 0.14$ \\
\hline
\end{tabular}

Table2. Descriptive Statistics for the Male Subjects

\begin{tabular}{|c|c|c|c|c|}
\hline Parameters & $\begin{array}{c}\text { VBL } \\
(\mathrm{mm}) \\
\text { Mean + SD }\end{array}$ & $\begin{array}{c}\text { H } \\
(\mathrm{mm}) \\
\text { Mean + SD }\end{array}$ & $\begin{array}{c}\text { SCD } \\
(\mathbf{m m}) \\
\text { Mean + SD }\end{array}$ & $\begin{array}{c}\text { Torg - Parlor } \\
\text { Ratio } \\
\text { Mean + SD }\end{array}$ \\
\hline C3 & $20.44 \pm 0.81$ & $12.73 \pm 1.82$ & $20.19 \pm 1.65$ & $0.96 \pm 0.13$ \\
\hline $\mathrm{C} 4$ & $20.76 \pm 1.90$ & $12.89 \pm 1.86$ & $19.55 \pm 1.78$ & $1.04 .94 \pm 0.13$ \\
\hline C5 & $20.52 \pm 2.00$ & $12.75 \pm 1.99$ & $19.49 \pm 2.08$ & $1.00 . \pm 0.12$ \\
\hline
\end{tabular}

Table3. Descriptive Statistics for Female Subjects

\begin{tabular}{|c|c|c|c|c|}
\hline Parameters & $\begin{array}{c}\text { VBL } \\
(\mathrm{mm}) \\
\text { Mean } \pm \text { SD }\end{array}$ & $\begin{array}{c}\text { H } \\
(\mathrm{mm}) \\
\text { Mean + SD }\end{array}$ & $\begin{array}{c}\text { SCD } \\
(\mathbf{m m}) \\
\text { Mean } \pm \text { SD }\end{array}$ & $\begin{array}{c}\text { Torg - Parlor } \\
\text { Ratio } \\
\text { Mean } \pm \text { SD }\end{array}$ \\
\hline C3 & $20.04 \pm 1.80$ & $12.73 \pm 1.88$ & $18.99 \pm 1.75$ & $0.94 \pm 0.13$ \\
\hline $\mathrm{C} 4$ & $19.00 \pm 2.10$ & $12.29 \pm 1.90$ & $18.5 \pm 1.98$ & $1.01 \pm 0.17$ \\
\hline $\mathrm{C} 5$ & $19.00 \pm 2.53$ & $12.15 \pm 1.91$ & $18.49 \pm 2.18$ & $0.97 \pm 0.26$ \\
\hline
\end{tabular}

Table4. Comparative Means of Parameters Using Age

\begin{tabular}{|c|c|c|c|c|c|c|c|c|c|}
\hline \multirow[t]{2}{*}{ AGE } & \multicolumn{3}{|c|}{ VBL } & \multicolumn{3}{|c|}{$\begin{array}{c}\mathbf{H} \\
(\mathbf{m m})\end{array}$} & \multicolumn{3}{|c|}{$\begin{array}{l}\text { SCD } \\
(\mathbf{m m})\end{array}$} \\
\hline & C3 & $\mathrm{C4}$ & C5 & C3 & C4 & C5 & C3 & C4 & C5 \\
\hline $21-30$ & \multicolumn{9}{|c|}{$18.9 \pm 0.6817 .9 \pm 1.1417 .3 \pm 1.2510 .8 \pm 0.6510 .5 \pm 0.6210 .5 \pm 0.7717 .9 \pm 0.3617 .2 \pm 0.7516 .91 \pm 59$} \\
\hline $31-40$ & \multicolumn{9}{|c|}{$20.0 \pm 0.1 \quad 19.13 \pm 0.3419 .20 \pm 0.3612 .6 \pm 0.4912 .2 \pm 0.3812 .0 \pm 0.1 \quad 19.1 \pm 0.41 \quad 18.5 \pm 0.518 .6 \pm 0.69$} \\
\hline $41-50$ & \multicolumn{9}{|c|}{$21.4 \pm 0.6620 .0 \pm 0.6120 .5 \pm 0.61 \quad 13.7 \pm 0.6713 .5 \pm 0.5013 .1 \pm 0.4920 .3 \pm 0.1 \quad 19.8 \pm 0.3920 .0 \pm 0.1$} \\
\hline $\begin{array}{l}51 \& \text { Above } \\
\text { Ab }\end{array}$ & \multicolumn{9}{|c|}{$22.8 \pm 1.3723 .1 \pm 1.2123 .4 \pm 1.2715 .5 \pm 0.9115 .1 \pm 0.8415 .1 \pm 0.8421 .5 \pm 1.2221 .5 \pm 1.2021 .5 \pm 1.22$} \\
\hline
\end{tabular}

\section{Conclusion}

The cervical vertebrae body length and height of the typical cervical vertebrae studied in this research work showed larger Canal vertebrae in men than women. On estimating the applicability of Torg Pavlov's ratio in our population. It was found to be reliable as a means to diagnose cervical stenosis for those whose values are less than 0.8 .

\section{REFERENCES}

[1] Evangelooulos DS, Kontovenitis P, Kouris S, Zlatidou X. Benneker I. M, Vlanis JA, Korres DS, Efsthapoulous N. Open Orthop J: 6: 250 - 254. (2012)

[2] Banerjee PS, Roychoudhury A, Preswilti KK, Karmaker SK Morphometric Analysis Of The Cervical Spine Of Indian Population By Using Computerized Tomography. J. Med. Atled Sci. 2:2 66. (2012)

[3] Torg JS, Pavlov H, Genvario SE et al Neurapraxia of the cervical spinal cord with transient quadriplegia. J. Bone Joint Surg Am 1986; 68: 1354 - 1370.

[4] Pavlov H, Torg JS, Robie B et al cervical canal stenosis determination with vertebrae body ratio method. Radiol 1987; 164: 771 - 775.

[5] Blackley HR, Plank LD, Robertson PA Determining the sagittal Dimensions of the canal of the typical cervical spine. The reliability of ratios of Anatomical measurements. J. Bone Joint Surg (Bor); 81 - B(1): 110 - 112. (1999) 
[6] Dahlan RH, Yudoyono F, Saputra PAE, Ompusunggu Se, Arifin MZ, Sutiono AB, Faried A. Morphometric Analysis of the corpus, spinal canal and Torg Ratio using mid sagittal cervical vertebrae CT Scan: Indonesian Population. Int. J Int. Health Sci. 2 (1) 36 - 39. (2014)

[7] Choudharys S, Kattimuthu P, kataria SK A radiographic study of sagittal diameter of cervical spinal canal in adult male population of Rajusthan. Asian J Med Res; 2 (1): 7 - 9. (2013)

[8] Song KJ, Choi BW, Kim SJ, Kim Ch, Kim Ys, Song JH. The relationship between spinal stenosis and neurological outcome in fraumatic cervical spine injury: an analysis using Paulor ratio, spinal cord area and spinal canal area. Clin Orthup Sury; 1(1): 11 - 18. (2009)

[9] Karabulut O, Karabulut Z. The variations OF Torg ratio with gender in patients with neck pair Dicle Tip Dergisi. 2007; 34 (4) 272 - 274.

[10] Wong TM, Leung HB, Wong WC Correlation between MRI and Radiographic measurement of cervical spine in cervical myelopathy patients. J Orthop Surg.; 12 (2) 239 -242. (2004)

[11] Tahjadi D, Onibala MZ Torg's ratio based on cervical lateral plain film in normal subjects. Universal medicina; 29 (1) 8 - 13. (2010)

[12] Aebli N, Wicki AG, Ruegg TB. Petrov N, Eiseniohr H, Krebs J. The Torg - Paulor ratio for the prediction of acute spinal cord injury after a minor trauma to the cervical. Spine J.; 13(6): $605-$ 612. (2013)

[13] Kathule MA, Joshi RA, Herekar NG Jadhav SS Dimensions of cervical spinal canal and their relevance in clinical practice. Int. J Recent Trends Sci. Tech.; 3(2): 54 - 58. (2012)

[14] Suk KS, Kim KT, Lee JN, Lee SH Kim JY. Revaluation of the Paulor ratio in patients with cervical myelopathy. Clin Orthop Surg,1(1): 6-10. (2009)

[15] Singh A, Tetreault L, Fehlings MG Fisher DJ, Skelly AC. Risk Factors for development of cervical spondylotic myelopathy: Rersults of a systemic review. Evid Based Spine Care J.; 3(3): $35-42$. (2012)

[16] Yue N - M, Tan S - B, Tan Chi-Song K, Tan C-T. The Torg - Paulor ratio in cervical spondylotic myelopathy and a Non-spondylotic Non Myelopathic population spine; 26(16): 1760 - 1764. (2001)

[17] Hukuda S, Xiang LF, Imai B, Katsuura A, Imanaka T Large Vertebral body, in addition to narrow spinal canal, are riskfactors for cervical myelopathy. J. Spinal Disord 9(3) 177 - 186. (1996)

[18] Castro FP JR, Ricciandi J, Brunet ME, Busch NT, Whitecloud TS $3^{\text {rd }}$. AM J Sport Med.; 25(5): $603-608 .(1997)$

[19] Herzog RJ, Wiens JJ, Dilingham MF et al Normal cervical spine morphometry and cervical spine stenosis in Asymptomatic professional football players. Plain film Radiography, multiplaner CT and MRI. Spine; 16: 178 - 186. (1991)

[20] Lim JK, Wong HK Variation of the cervical Spinal Torg ratio with gender and Ethnicity. Spine $J$, 4(4) 398 - 401. (2004)

[21] Hukude \& Koshima Sex disripancy in the canal/body ratio of the cervical spine implicating the prevalence of cervical myelopathy in men. Spine; 1:27(3) 250 -253. (2002)

[22] Gour KK, Shrivastiva SK, Thokare AE, size of cervical vertebral cana - measurements in lateral cervical radiographs and dried bones. Int J Boil Med Res.; 2(3): 778 - 780. (2011)

[23] Magbool A Arthur z, Hussanl Migsagital diameter of the cervical spinal canal and Torg's ratio of the cervical spine in Pakistanis. Pakistan J Med Sci; 19(3): 203 - 210. (2003)

[24] Golo S, Umehara J, Aizawat, Kokubon S Comparison of cervical spinal canal diameter between younger and elder generation of Japanese. J orthop Sci; 15(1) 97 - 103. (2010) 